\title{
Poder e Discurso: uma análise de conteúdo do discurso de posse dos Ministros das Relações Exteriores do Brasil (2003-2016)
}

\author{
Pedro Fonseca* \\ * Instituto de Estudos da Ásia, Universidade Federal de Pernambuco, Brasil
}

\begin{abstract}
Resumo
O presente artigo busca analisar os discursos de posse dos Ministros das Relações Exteriores do Brasil no período que corresponde de 2003 até 2016, posse do ex-Ministro José Serra. Utilizando a análise de conteúdo de discurso, o trabalho busca analisar as diretrizes da Política Externa dos governos Lula, Dilma e Temer. O trabalho busca corroborar com a tese de que no governo do Partido dos Trabalhadores (PT) as diretrizes da política externa brasileira foram num sentido de relações mais sul global, enquanto no governo do Partido do Movimento Democrático Brasileiro (PMDB) observamos indícios de uma mudança nessas diretrizes, priorizando relação com o centro do capitalismo. Para isso, foi utilizado o método de análise de conteúdo, proposto por Bardin (1977) e o software IRAMUTEQ.
\end{abstract}

Palavras-chave: análise de discurso; discurso; MRE; poder; política externa

\begin{abstract}
This article analyzes speeches of tenure of the Ministers of Foreign Affairs of Brazil made between 2003 and 2016, in the inaugural speech of former Minister José Serra. Using discourse analysis, the paper analyzes guidelines of the Foreign Policy of the Lula, Dilma and Temer governments. The paper seeks to corroborate the thesis that in the government of the Workers' Party (PT) the guidelines of the Brazilian foreign policy emphasize global South relations, while in the government of the Party of the Brazilian Democratic Movement (PMDB) these guidelines prioritize relations with the centers of capitalism. To this end, we used the content analysis method proposed by Bardin (1977) and the software IRAMUTEQ.
\end{abstract}

Keywords: foreign policy; MRE; power; speech; speech analysis 


\section{Introdução ${ }^{[1]}$}

O conceito de política externa é amplo, podendo ser definido de diferentes formas, como mostra Sousa (2016). Wilhelmy (1988 apud Oliveira, 2005, p. 5) define política externa como um "conjunto de atividades políticas, mediante as quais cada Estado promove seus interesses perante os outros Estados". Russell (1990) amplia esse conceito, em que passa a considerar política externa como "a área particular da ação política dos governos" (Oliveira, 2005); enquanto Hill (2003, p. 3) define política externa como "conjunto das relações oficiais externas conduzidas por um ator independente (usualmente um Estado) nas relações internacionais". Finalmente, Ribeiro (2016) pontua que a política externa é um conjunto de ações e decisões de um determinado ator específico, sendo esse ator não sendo apenas aos Estados, mas também outras organizações internacionais e elementos de natureza doméstica.

Observa-se, através dessas definições, um protagonismo central do Estado no desenvolvimento da política externa, e, no Brasil o órgão responsável por isso é o Ministério das Relações Exteriores (MRE), também conhecido como Itamaraty, que é um órgão vinculado ao poder Executivo federal responsável pela política externa brasileira. Segundo o Regimento Interno da Secretária de Estado das Relações Exteriores (RISE) ${ }^{[2]}$, através do Art. 1, declara que o propósito do Ministério é:

[...] auxiliar o Presidente da República na formulação da política exterior do Brasil, assegurar sua execução, manter relações diplomáticas com governos de Estados estrangeiros, organismos e organizações internacionais e promover os interesses do Estado e da sociedade brasileiros no exterior.

A partir disso, pode-se observar que o discurso de posse do Ministro das Relações Exteriores demonstra aos atores internacionais como o governo pretende se portar sobre uma série de questões relacionadas à política externa, sejam elas no âmbito econômico, político ou humanitário. Assim, como afirma Silva (2014):

Já que o discurso é socialmente construído e, portanto, moldado pelos processos da prática social e do contexto político, podemos utilizá-lo como ferramenta de análise da ação dos atores encarregados da prática política (Presidentes, Ministros, entre outros) e dos fatores que a impactam (Silva, 2014. p. 3).

Desse modo, o presente trabalho busca analisar, através da análise de conteúdo dos discursos de posse dos ministros dos governos Lula, Dilma e Temer, quais as diretrizes formuladas para a política externa brasileira. $\mathrm{O}$ artigo analisou três discursos de posse, os discursos do ex-Ministro Celso Amorim, que esteve presente no governo Lula (2003-2010), do ex-Ministro Antônio Patriota, que foi Ministro do governo Dilma (2011-2016) no período de $1 .^{\circ}$ de janeiro de 2011 até 26 de agosto de 2013 e do ex-Ministro do governo Temer (2016 - atual), José Serra que esteve a frente

1. Agradeço a Nayanna Sabiá e Neto Galdino os inúmeros comentários e incentivos. Agradeço ainda aos pareceristas anônimos da Revista Portuguesa de Ciência Política pelas excelentes sugestões. Quaisquer incorreções remanescentes são de minha total responsabilidade.

2. Disponível em: <www.itamaraty.gov.br/images/RISE.pdf> (acesso em 20 nov. 2016). 
do Itamaraty no período de 12 de maio de 2016 até 22 de fevereiro de 2017. O motivo para não integrar nas análises os discursos dos ex-Ministros do governo Dilma, Luiz Alberto Figueiredo e Mauro Vieira deve-se ao fato de que seus discursos seguirem as diretrizes do ex-Ministro Antônio Patriota. Além disso, o artigo optou por analisar o governo interino de Michel Temer devido à ruptura institucional, porém traumática, tendo em vista que no sistema presidencialista, o impeachment é o único dispositivo legal para destituir um presidente de seu cargo. Assim, é de se esperar que tal fato tenha um impacto na condução da política externa.

A hipótese a ser testada será a de que os governos Lula e Dilma se basearam em uma política externa mais voltada a cooperação regional e para o fortalecimento das relações Sul-Sul. Enquanto no governo Temer há indícios de que se baseia numa cooperação mais Norte-Sul e com um maior enfoque no comércio e pragmatismo econômico. Para o teste da hipótese, foi utilizado o método de Análise de Conteúdo e o auxílio do software IRAMUTEQ, tanto na construção das análises, como análise de similitude, nuvem de palavras e de clusters. O referencial teórico a ser seguido será Bardin (1977), devido ao fato da autora ser referência nos trabalhos de análise de conteúdo. Além disso, o artigo propõe realizar um breve contexto histórico sobre a situação interna e externa do país em cada período dos discursos de posse, pois a análise de conteúdo "tem por princípio uma abordagem investigativa que não negligencia as influências socioespaciais e o contexto em que determinado discurso se insere" (Silva, Ribeiro \& Carvalho, 2014, p. 3).

Por último, o artigo propõe, dentro de suas limitações, ampliar o debate sobre a política externa brasileira dentro da academia, principalmente entre jovens pesquisadores, além disso, busca, junto a outros pesquisadores, estender o debate sobre política externa para a sociedade, tendo em vista que a política externa pode ser considerada uma política pública (Costa da Silva, 2015).

\section{Metodologia}

O método a ser utilizado nessa pesquisa será o método de Análise de Conteúdo, que tem o seu o desenvolvimento no início do século xx nos Estados Unidos da América (EUA). Segundo Silva et al. (2014), é durante a I Guerra Mundial que a Universidade de Colúmbia torna-se pioneira nesses estudos quantitativos de material de imprensa e propaganda, caracterizados por intenso rigor matemático.

Moraes (1999) afirma que a análise de conteúdo faz parte de uma busca teórica e prática, com um significado especial no campo das investigações sociais. Para Weber (1990, p. 19) a análise de conteúdo envolve o desenvolvimento de uma série de procedimentos para fazer inferências a partir de textos. Moraes (1999) vai mais além e afirma que "a matéria-prima da análise de conteúdo pode constituir-se de qualquer material oriundo de comunicação verbal ou não-verbal." No entanto, ressalta que os dados chegam ao investigador em estado bruto, necessitando, um refinamento dos mesmos para facilitar a compreensão, interpretação e inferência. (Moraes, 1999).

Já Olabuenaga e Ispizúa (1989) argumentam que a análise de conteúdo pode ser definida como uma técnica para ler e interpretar uma vasta classe de documentos, cujo o objetivo é adquirir conhecimento sobre certos aspectos e fenômenos da vida 
social. Assim, a análise de conteúdo seria um método válido e replicável para a realização de inferências específicas sobre o texto ou outras propriedades do objeto de estudo. (Krippendorf, 1969).

Por fim, Bardin (1977, p. 38) refere-se a Análise de Conteúdo como "um conjunto de técnicas de análise das comunicações, que utiliza procedimentos sistemáticos e objetivos de descrição do conteúdo das mensagens". Para a autora, a Análise de Discurso é composta de três fases: a pré-análise, a exploração do material e o tratamento dos resultados. Segundo Silva (2014):

A pré-análise, que corresponde a organização do material, como a escolha dos documentos e do objetivo; a exploração do material, a fase mais longa e complexa com a classificação e codificação das fontes; e o tratamento dos resultados, por meio da dedução e da interpretação dos dados. A intenção da análise é realizar deduções lógicas, transformando o conteúdo dos discursos em dados quantitativos e/ou analisando-os de forma qualitativa (Silva, 2014, p. 3)

Seguindo a metodologia proposta por Bardin, os discursos de posse foram coletados nos sites do Ministério das Relações Exteriores ${ }^{[3]}$ e da Fundação Alexandre de Gusmão (FUNAG) ${ }^{[4]}$ e sofreram uma leitura prévia. Em seguida, para analisar o conteúdo dos discursos de posse, foi utilizado o software gratuito de pesquisa IRAMUTEQ $^{[5]}$ que possui fonte aberta e foi desenvolvido por Pierre Ratinaud. As análises feitas com o software foram nuvem de palavras e análise de similitude.

A análise de nuvem de palavras organiza as palavras segundo sua frequência, ou seja, as palavras que mais aparecem no texto terão um tamanho proporcionalmente maior do que outras palavras que aparecem menos vezes. Já análise de similitude, proposta por Claude Flament, baseia-se na teoria dos grafos (Marchand \& Ratinaud, 2012), que permite identificar "como concorrências entre os elementos e seu resultado traçam indicações da conexidade entre as palavras, auxiliando na identificação da estrutura de um corpus textual." (Justo \& Camargo, 2014. p. 13). Ou seja, através do processamento de indicadores estatísticos apresentam as relações entre as palavras, formando uma árvore de palavras com ramificações, a partir da relação que uma tem com a outra. Assim, as palavras que aparecem em destaque, demonstram maior centralidade e importância para a ligação estabelecida entre os elementos. Desse modo, quanto maior o tamanho da fonte, maior a sua frequência e contribuição para a formação das conexões da respectiva árvore (Porcino, 2016). Em resumo, como cita Pontes, Oliveira e Gomes (2014), essa técnica pode ser definida como destinada à averiguação da "quantidade de laços ou conexões que um dado elemento mantém com outros elementos da representação”.

3. <www.itamaraty.gov.br>.

4. <funag.gov.br>.

5. Interface de R pour les Analyses Multidimensionnelles de Textes et de Questionnaires. 


\section{A Política Externa Brasileira (PEB)}

Quando debate-se sobre a PEB, é necessário pontuar certas características que a definem como tal. Um importante fator é a tradição diplomática, ou seja, continuidade e coerência da práxis do Itamaraty durante o tempo, como afirmado por San Tiago Dantas (1962), quando afirma que "[...] a conduta internacional do Brasil tem sido a de um Estado consciente dos próprios fins, graças à tradição administrativa que se tornou depositária a Chancelaria Brasileira[...]" (Dantas, 1962, p.17). Essa ação contínua ao longo do tempo do Ministério das Relações Exteriores (MRE), como "instituição permanente da nação, apta a representar os seus interesses [...]" (Lafer, 2014. p. 21), contribuiu para a construção da identidade internacional do Brasil.

A formação do Brasil, enquanto Estado, esteve intimamente ligada com o desenvolvimento de uma política externa, pelo menos na constituição das fronteiras. É válido pontuar que os diplomatas foram agentes primordiais, sendo responsáveis por consolidar a titulação jurídica do território pertencente ao Estado, seja por meio de Tratados, seja pela arbitragem internacional. Desse modo, junto aos navegantes, os primeiros a chegarem a América do Sul, e os bandeirantes, que ampliaram o território bem além do Tratado de Tordesilhas (1494) entre as Coroas de Portugal e Espanha; expandindo, assim, o território brasileiro. Cabe destacar a figura histórica de Alexandre de Gusmão, que foi diplomata na época do Brasil Colônia. Gusmão Tratado de Tordesilhas, para a delimitação das posses de cada reino, e, consequentemente, dos países que surgiriam, após os processos de independência das colônias. Por esse motivo, Gusmão é tido como o "avô da diplomacia brasileira", como pontuado por Araújo Jorge (1948).

A relevância da diplomacia na história da formação do Brasil, como argumenta Lafer (2014), dá-se pelo fato de que a fixação de fronteiras é o princípio básico para se pressupor a diferença entre espaço nacional (interno) e o mundo (externo). Assim, o papel que a diplomacia, em especial o Barão do Rio Branco ${ }^{[6]}$, desempenhou na fixação territorial brasileira de maneira diplomática, algo pouco convencional para época, tendo em vista as extensões territoriais que o país detém, e comparado a países continentais, como Rússia e China, que estabeleceram suas fronteiras predominantemente por meio de conflitos. Além disso, destacam-se as grandes diferenças culturais entre os vizinhos da região, como a questão linguística e além do fato de o Brasil ter sido um Império após a independência, enquanto os demais tornaram-se Repúblicas.

Após a independência, a ação diplomática do período da República desenvolve-se de maneira a reconhecer que o Brasil é um país latino-americano e, a partir disso, o país deve se aproximar dos seus vizinhos para desenvolver uma relação pacífica. Assim, Rio Branco, em 1909 em um discurso, proferiu que a paz é uma condição essencial ao desenvolvimento dos povos, e os países latino-americanos necessitavam - e

6. Arbitragens internacionais: Argentina, 1895; França - Guiana Francesa, 1900. Tratados e limites: Bolívia - Tratado de Petrópolis, 1903; Peru, 1904/1909; Grã-Bretanha - Guiana Inglesa, 1904; Venezuela, 1905; Holanda - Guiana Holandesa, 1906; Colômbia, 1907 e Uruguai, 1909. 
necessitam - crescer rapidamente ${ }^{[7]}$. Lafer $(2014$, p. 52) pontua que "[...] um clima pacífico na América do Sul é condição importante para favorecer o desenvolvimento do espaço nacional [...]”. Logo, essa estratégia, com forte inspiração grociana ${ }^{[8]}$, foi um dos pontos seguidos pelo Brasil pós-Rio Branco, buscando transformar as fronteiras brasileiras de fronteiras-separação para fronteiras-cooperação, manifestando-se em arranjos diplomáticos e associações, principalmente nos de comércio e de investimento. Tais arranjos aparecem com mais intensidade a partir da década de 1960, junto à primeira onda do regionalismo.

Podem ser destacadas a Associação Latino-Americana de Livre-Comércio (ALALC), que foi substituída posteriormente pela Associação Latino-Americana de Integração (ALADI) ${ }^{[9]}$ e os tratados, como o Tratado celebrado com o Paraguai, em 1973, que levou à construção da hidrelétrica de Itaipu, e o acordo tripartite entre Argentina, Brasil e Paraguai, de 1979, que compatibilizou as usinas de Itaipu e Corpus. Outro tratado que vale ser mencionado é o Tratado de Tlatelolco, de 1967, que proibiu a confecção e armazenamento de armamentos nucleares na América Latina. Desse modo, a partir da República, a diplomacia brasileira passa a ver a América do Sul como espaço de paz e desenvolvimento, sendo essa uma constante da política externa brasileira e um componente forte da identidade internacional do Brasil (Lafer, 2014).

Outro fator importante a ser destacado é o comportamento do Brasil perante relações desiguais. Tal dinâmica possibilitou o surgimento de um novo paradigma para a identidade internacional brasileira, que seria "uma visão sobre o mundo e o seu funcionamento, e de que esta visão é importante para resguardar e encaminhar os interesses específicos do país" (Lafer, 2014, p. 74). Fruto da Primeira Grande Guerra e da consequente Paz de Versailles, o Brasil encontrava-se em uma nova dinâmica internacional em que havia uma distinção entre potências beligerantes com interesses gerais, ou seja, interesses que abarcavam todo o mundo geopolítico, e potências beligerantes com interesses limitados que não abarcavam interesses a nível mundial. Assim, a partir dessa nova conjuntura, o Brasil, como potência média a nível mundial e de grande relevância regional, busca exercer seu soft-power para defender seus interesses na mesa geopolítica, sendo o principal meio para isso o Direito, além de desempenhar um papel como articulador de consensos, como denota Fonseca Jr. (1982). Esse papel foi de grande importância, como por exemplo, em 1993, na Confe-

7. Obras do Barão do Rio Branco, Vol. IX, Discursos. Rio de Janeiro: Ministério das Relações Exteriores, p. 190.1948.

8. Diferente das tradições kantianas, universalista, e hobbessiana, realista, a tradição grociana, universalista, acredita na possibilidade de cooperação. Logo, trabalha-se não com a ideia de uma guerra sem tréguas ou de uma paz perpétua, mas de uma partilha de interesses e de valores comuns, que permitiria o equilíbrio entre o conflito e o interesse.

9. A ALADI foi instituída pelo Tratado de Montevidéu em 1980, substituindo o Tratado assinado em 18 de fevereiro de 1960, pelo qual havia sido criada a ALALC. Essa substituição estabeleceu um novo ordenamento jurídico operacional para dar continuidade ao processo de integração. Disponível em: <http:// www.aladi.org/nsfaladi/preguntasfrecuentes.nsf/009c98144e0151fb03256ebe005e795d/cf2ded02ef8e4a6c03256ed100613e5d?OpenDocument> (acesso em: 13 de maio 2017). 
rência de Viena sobre os Direito Humanos e, em 1990, na Rodada Uruguai do General Agreement on Tariffs and Trade (GATT) ou Acordo Geral de Tarifas e Comércio.

No período que corresponde a ditadura civil-militar, a política externa brasileira representou os interesses do grupo que naquele momento se encontrava no controle do Estado (Miyamoto, 2013). No entanto, é necessário salientar que em todos os cinco governos do período civil-militar houve elemento de continuidade e de mudanças. De maneira geral, a bibliografia especializada divide as políticas externas dos governos do regime militar em política de alinhamento automático, diplomacia da prosperidade, diplomacia do interesse nacional, pragmatismo responsável e pragmatismo ecumênico, em que cada rótulo representa um governo militar.

O governo do Marechal Castello Branco (1964-1967) apresentou características de política externa distinta dos outros governos militares, como pontua Luiz (2011). Baseada na aproximação ideológica com os EUA, incorporando o discurso anticomunista, entrando, assim, na lógica do conflito leste-oeste, o período é classifica por Paulo Vizentini como uma "política externa interdependente" (2004, p. 21) e por Amado Cervo como "um passo fora da cadência" (1992, p. 332). Além disso, outra característica do período é de segurança hemisférica na lógica da política externa.

Em seguida temos a diplomacia da prosperidade, do governo Costa e Silva (19671969), que é marcado por mudanças em suas bases políticas (Luiz, 2011). Pinheiro (2004) demonstra que houve uma série de reincorporações de teses de cunho nacionalista no modelo de desenvolvimento do período Costa e Silva, buscando trilha um caminho mais independente para o Brasil. Esse enfoque no nacional-desenvolvimentismo é fruto das consequências geradas pelo governo Castello Branco e sua abertura demasiada ao capital estrangeiro.

O período que corresponde o governo Médici (1969-1974), denomina-se a política externa como diplomacia do interesse nacional. Do ponto de vista de política interna, o discurso ideológico anticomunista continua forte e, por vezes, é até radicalizado. Luiz (2011, p. 7), pontua que "boa parte dos autores julga o período Médici como período de construção das bases para o que viria a ser o pragmatismo responsável do governo seguinte". No âmbito da política externa a perspectiva ideológica foi diluída, dando mantendo a importância do nacionalismo de fins. Para Vizentini (2004) é nesse momento que surge a definição do modelo do tripé econômico, ou seja, empresas estatais, empresas transnacionais e capital privado nacional dando respaldo ao desenvolvimento econômico.

O governo Geisel (1974-1979) já sofria com o esgotamento do chamado milagre econômico, além das consequências do choque do petróleo e do colapso de Bretton Woods. Desse modo, Luiz (2011, p. 7) argumenta que "a importância do então denominado Pragmatismo Responsável pode ser interpretada tanto por retomar alguns dos princípios da Política Externa Independente, como por manter algumas de suas características [...].”. É no governo Geisel que abandona-se as fronteiras ideológicas, focando apenas no pragmatismo e no realismo.

Por fim, temos o governo do General João Batista Figueiredo (1979-1985), que no que tange à política externa, manteve a linha de atuação do pragmatismo responsável (Luiz, 2011). O governo Figueiredo manteve a base pragmática do governo 
anterior, mas aprofundou as relações sul-sul. Outro ponto importante foi a perda de tomada de decisão do Itamaraty, principalmente no que tange questões econômicas que passaram para outros setores da burocracia estatal, como pontua Cervo (1992) e Vizentini (2004).

A década 1990 representou o retorno do bilateral-hemisférico. O Brasil, a partir de uma nova dinâmica com o fim da guerra fria, em que os EUA são alocados ao posto de única potência global,é realocado no Sistema Internacional, sendo percebido como uma nação periférica. Desse modo, essa nova configuração, fez com que o país se adapta-se as condições para superar a década perdida. Assim, houve uma forte guinada neoliberal. Na década de 1990, o Brasil passa por um processo de impeachment que afeta sua credibilidade de democracia recente, para contornar isso, o governo Franco da continuidade ao Mercosul, que possuía conteúdo tanto de autonomia quanto de alinhamento como pontua Pecequilo (2008, p. 138). No governo FHC há um objetivo de melhorar a imagem do país para criar canais com os países desenvolvidos. Um dos desses pontos é ratificação do Tratado de Não Proliferação em 1998 e aliado a isso a estabilidade econômica através do Plano Real.

A partir do que foi exposto, nota-se certas características da PEB, sendo elas: o juridicismo, o pacifismo, a continuidade e a coerência. Contudo, Lacerda (2001), pontua que essas características da política externa brasileira, embora sejam tradicionais, ou seja, embora façam parte de algo que se poderia chamar de uma "tradição da diplomacia brasileira”, não são sempre automáticas nem têm uma aplicação constante ao longo do tempo. Assim, a diplomacia possui indeterminações que devem ser percebidas e aceitas como sendo parte do desenvolvimento da área, assim como ocorre no campo da política. Além disso, membros do corpo diplomático já indicaram como esses traços da PEB não são "infalíveis" ou "automáticos” (Lacerda, 2001 apud Almeida, 1998).

\section{Análise}

"A linguagem tem poder político."

Hansen, 2012

O primeiro discurso a ser analisado é do ex-ministro Celso Amorim, que esteve no cargo de Ministro das Relações Exteriores durante todo o governo Lula (2003-2010). Ao analisar a nuvem de palavra, nota-se as palavras "desenvolvimento" e "social" (Figura 1) como destaque. Além disso, palavras como "cooperação" e "integração" (Figura 1) aparecem de maneira secundária na nuvem.

Pode-se, a partir dessa análise secundária, tendo em vista que análise primária foi leitura preliminar dos textos, denotar indícios de que as diretrizes da política externa brasileira no governo Lula basearam-se em um tom de cooperação com os atores políticos internacionais, tendo como prioridade as relações sul-sul e a parceria com países emergentes, como argumentam Ribeiro e Júnior (2013). Além disso, há indicativos de que a política externa também caracterizou-se pela busca de uma "autonomia pela diversificação”. Esse termo é definido por Vigevani e Cepaluni (2007) como: 
[A] adesão do país aos princípios e às normas internacionais por meio de alianças sul-sul, inclusive regionais, e de acordos com parceiros não tradicionais (China, Ásia-Pacífico, África, Europa Oriental, Oriente Médio etc.), pois acredita-se que eles reduzem as assimetrias nas relações externas com países mais poderosos e aumentam a capacidade negociadora nacional (Vigevani \& Cepaluni, 2007, p. 283).

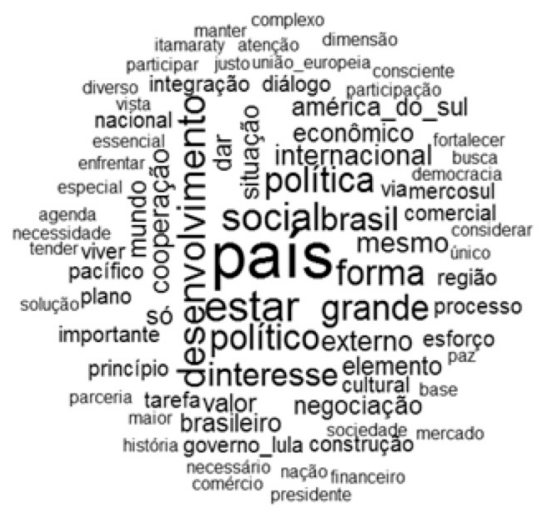

Figura 1. Nuvem de Palavras - Celso Amorim

Fonte: Ministério das Relações Exteriores e FUNAG.

Rinaldi (2015) aponta os procedimentos cruciais que balizaram as diretrizes da política externa do governo Lula. Seriam eles, a aproximação brasileira com seus vizinhos da América do Sul nos setores econômico e político; o desenvolvimento conjunto com países no mesmo patamar econômico brasileiro, no âmbito das relações sul-sul; a manutenção das relações saudáveis com os países desenvolvidos; a participação brasileira nos principais organismos embaixadas, além de uma maior participação em fóruns multilaterais, como por exemplo, a Organização Mundial do Comércio (OMC) internacionais; e, por fim, a difusão de cooperação técnica, humanitária e educacional (Ribeiro, 2016).

Ao analisar o discurso de Amorim, pode-se notar o desejo de um papel de maior protagonismo do Brasil nas Relações Exteriores. Esse protagonismo permitiu que o país chegasse ao posto de potência emergente, através de uma Política Externa "ativa e altiva", como foi dito pelo então chanceler Celso Amorim. Assim, como argumentam Forman e Myers (2016), o Brasil, no governo Lula, emergiu como uma potência do Sul Global, em que a política externa transformou o país em um ator de importante relevância internacional ao passo que ia aumentando sua inserção na África e na Ásia, ao abrir várias embaixadas, além de uma maior participação em fóruns multilaterais, como por exemplo, a Organização Mundial do Comércio (OMC). 


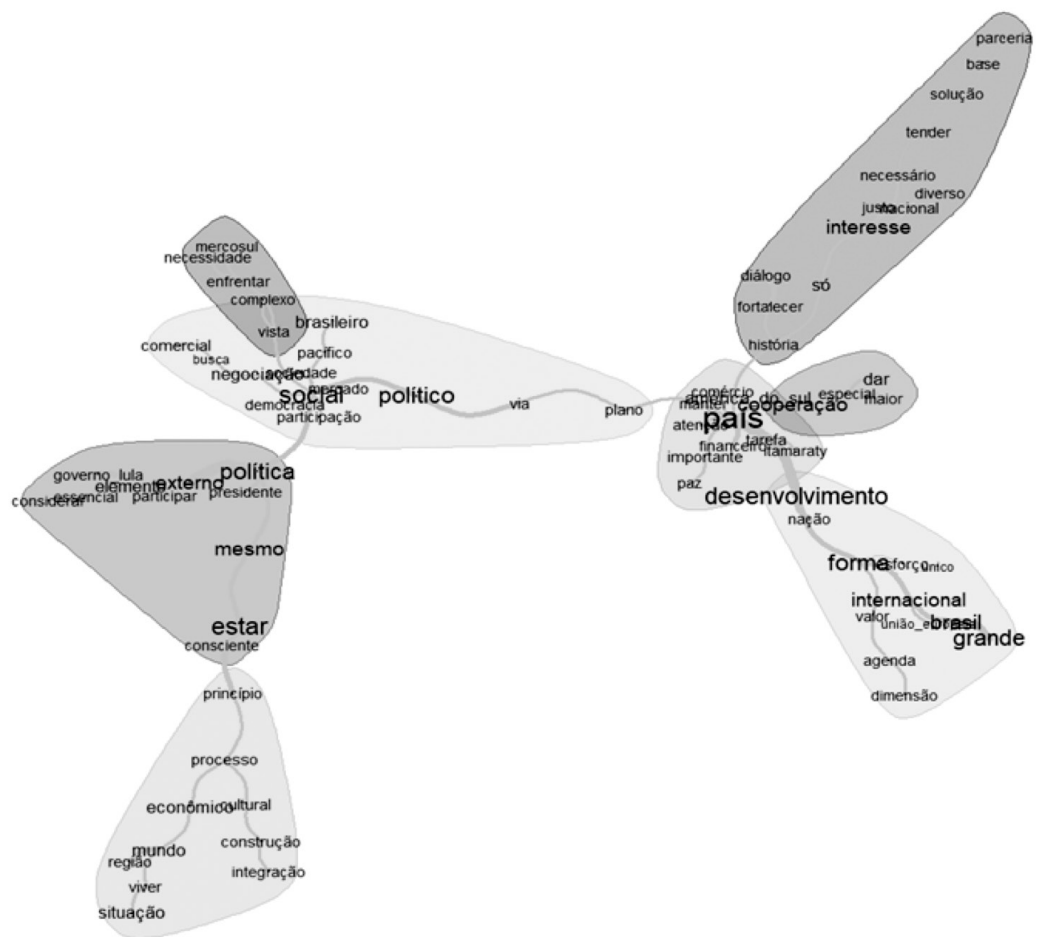

Figura 2. Similitude - Celso Amorim

Fonte: Ministério das Relações Exteriores e FUNAG.

$\mathrm{Na}$ esfera econômica, Forman e Myers (2016) afirmam que o Brasil se tornou uma das mais importantes potências econômicas emergentes do Ocidente, e que essa situação foi utilizada para aumentar a participação e a presença do Brasil no cenário global. As autoras argumentam que:

Como membro fundador do G20 e força motriz por trás da criação do IBAS e da União das Nações Sul-Americanas, o Brasil era, em meados dos anos 2000, um poder emergente, tanto dentro de instituições internacionais estabelecidas quanto de instituições emergentes buscando questionar os desequilíbrios do sistema internacional (Forman \& Myers, 2016, p. 12).

Além disso, na lógica de cooperação sul-sul, durante o governo Lula, foi criada a União das Nações Sul-Americanas (UNASUL), além do fortalecimento do Mercado Comum do Sul (MERCOSUL) e, ainda no âmbito regional, deu-se continuidade à Iniciativa para a Integração da Infraestrutura Regional Sul-Americana (IIRSA) (Ribeiro, 2016). Já no âmbito internacional, criou-se o Fórum de Diálogo Índia-Brasil-África do Sul (IBAS) e o BRICS, grupo composto por Brasil, Rússia, Índia, China e África do Sul. Todos esses esforços geraram um enorme intercâmbio nas mais diferentes áreas, como por exemplo, tecnologia, segurança e comércio. 
Amorim (2013) afirma que esses espaços de diálogo permitiram a aproximação de países de diferentes regiões, que devido a questões histórico-culturais e, principalmente, carências e aspirações possuíam pontos em comum, mas devido à falta de espaços que permitissem um diálogo entre eles, apenas comunicavam-se em fóruns multilaterais. Além disso, essas iniciativas de cooperação sul-sul permitiram ao Brasil ter uma maior projeção nessas regiões. Assim, a partir dessa inserção Sul-Sul, o Brasil mantém seu caráter universalista no âmbito externo (Cervo \& Lessa, 2014).

Nota-se também um destaque com a pauta social, representada pelo próprio uso da palavra "social" (Figura 1). Esse é um importante ponto a ser analisado visto que, foi em grande medida, a principal plataforma de campanha do governo Lula e sua maior vitrine posteriormente. Tendo o Brasil virado exemplo de um projeto social bem-sucedido, devido as grandes reduções nas taxas de desigualdade, em que programas como Bolsa Família, que desempenharam um grande papel nessa redução, foram reconhecidos por órgãos internacionais ${ }^{[10]}$. Esse destaque sobre as causas sociais, reflete-se também na Figura 2, em que nota-se o termo "social" como um dos eixos principais do discurso, ao lado de "político e "Brasil".

Em seguida, analisando o discurso de Antônio Patriota, ministro do governo Dilma, (2011-2016), no período entre 1. ${ }^{\circ}$ de janeiro de 2011 até 26 de agosto de 2013, notam-se certas mudanças de discurso, apesar de o partido que estava no governo, o Partido dos Trabalhadores (PT), ser o mesmo do ex-presidente Lula. Observa-se um destaque maior para a palavra "cooperação" (Figura 3) e um grande destaque para a palavra "econômico" (Figura 3).

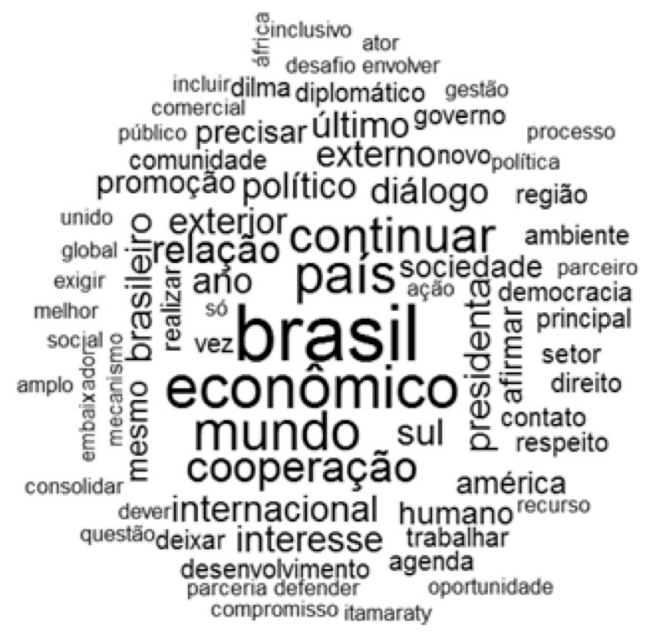

Figura 3. Nuvem de Palavras - Antônio Patriota

Fonte: Ministério das Relações Exteriores e FUNAG.

10. Disponível em: <https://nacoesunidas.org/programa-bolsa-familia-e-exemplo-de-erradicacao-de-pobrezaafirma-relatorio-da-onu/> (acesso em 5 dez. 2016). 
Pode-se argumentar que esse destaque na palavra "econômico" (Figura 3) é devido as consequências que o país já vinha sofrendo em decorrência da crise econômica de 2008 que, apesar de não ter sentido de imediato seus efeitos, já havia uma preocupação com declínio econômico ${ }^{[11][12]}$, que, no decorrer dos mandatos, foi sendo confirmada. A figura 4 também destaca o termo "econômico", sendo esse, ao lado de "Brasil", o eixo principal do discurso.

Essa queda nos índices econômicos refletiu-se na PEB, afetando a capacidade de exportação e cooperação técnica. Para Cervo e Lessa (2014), houve um "declínio relativo" do papel do Brasil no âmbito externo. Tal declínio pode ser observado através da diplomacia presidencial, que é definia por Danese $(1999$, p. 51) como a "condução pessoal de assuntos de política externa, fora da mera rotina ou das atribuições ex-officio, pelo presidente, ou, no caso de um regime parlamentarista, pelo chefe de estado e/ou pelo chefe de governo".

Através da análise do número de viagens que a Presidente Dilma Rousseff realizou, Cornetet (2014), demonstra que em comparação ao governo Lula I (2003-2006) houve uma redução de $31 \%$, enquanto se observarmos com o governo Lula II (20072010) nota-se uma redução de 55\% no número de viagens nos primeiros três anos de governo, ou seja, Lula no seu primeiro mandato viajou 111 vezes e no segundo 160; enquanto Dilma viajou 63.

Além disso, Cometet (2014) levanta outros dados para demonstrar esse declínio, como por exemplo, representações brasileiras no exterior, e seu crescimento e a quantidade de vagas ofertadas no Instituto Rio Branco, havendo uma queda de 50\%, em comparação ao primeiro governo Lula e $25 \%$ em relação ao segundo. Apesar dessa última variável necessitar de um teste de hipótese, segundo Cornetet (2014), autores como Stuenkel (2014) defendem que a redução do número de vagas no Instituto Rio Branco é um indicativo de contenção da política externa (Cornetet, 2014).

11. Disponível em: <http://www.brasil.gov.br/economia-e-emprego/2011/11/saida-para-crise-economica-e-combater-o-desemprego-diz-presidenta> (acesso em: 23 de Abr. 2017).

12. Disponível em: <http://www.valor.com.br/valor-investe/casa-das-caldeiras/1034948/2008-e-2011-sao-crises-com-impactos-distintos-sobre-o-brasi> (acesso em: 23 de Mai. 2017). 


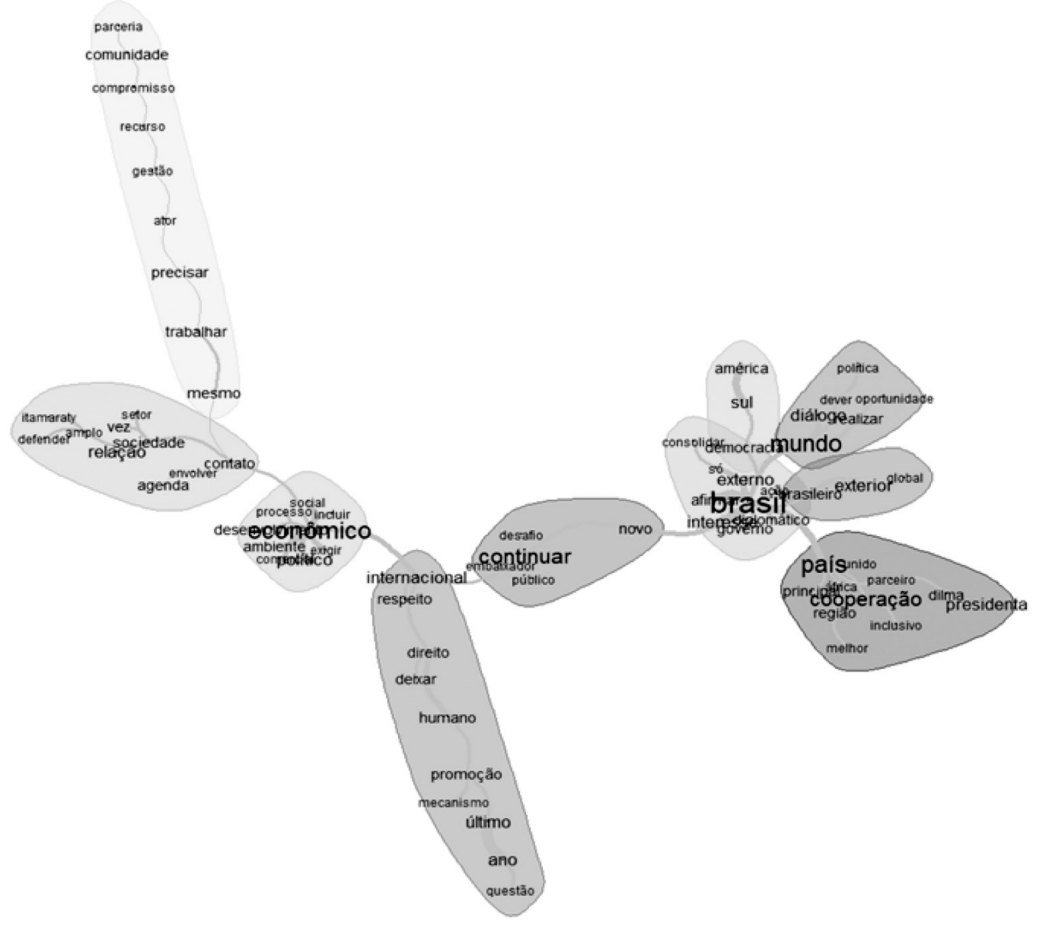

Figura 4. Similitude - Antônio Patriota

Fonte: Ministério das Relações Exteriores e FUNAG.

No entanto, as mudanças não possuem uma grande significância, visto que o mote do discurso caminha também para diretrizes com tons mais cooperativos e de ajuda mútua, como observa-se, por exemplo, na questão dos Direitos Humanos, que, como demonstrada por Silva (2014), continuava a ser pautada pelo princípio da não intervenção, porém acompanhada pela noção de indiferença, assim como durante o governo Lula. Além disso, como apontado por Ribeiro (2016), Dilma também deu continuidade na cooperação sul-sul com a criação do Banco dos BRICS e de um fundo de investimento para enfrentamento de crise; o fortalecimento brasileiro em iniciativas como a UNASUL e na Comunidade dos Estados Latino-Americanos e Caribenhos (CELAC), representando a aliança com os países da região. Por fim, observa-se também uma continuação no campo da cooperação com a África, com iniciativas como o Programa PAA-África ${ }^{[13]}$, apesar do recuo de novas iniciativas (Ribeiro, 2016; Saraiva, 2014).

13. Programa que busca promover a segurança alimentar e nutricional, além da geração de renda para agricultores e comunidades vulneráveis em países africanos. O PAA-África foi inspirado pela experiência brasileira bem-sucedida do "Programa de Aquisição de Alimentos (PAA)". 
Assim, como afirma Rezende (2016), “é verdade que a [Política Externa Brasileira] PEB de Dilma Rousseff não prosseguiu com o protagonismo dos anos Lula. Mas também não regrediu nos avanços feitos”. Já Cornetet (2014, p. 140) argumenta que houve uma "contenção na continuidade", ou seja, "embora tenha mantido a continuidade no que tange à busca dos objetivos nacionais de autonomia e de desenvolvimento, se tornou menos propositiva e menos ousada.". Por fim, como cita Saraiva (2014):

Em termos propriamente de política externa as mudanças foram progressivas. O primeiro movimento da diplomacia foi de continuidade e, segundo Spektor, a diplomacia de Dilma Rousseff não teria tido uma - distinção conceitual - da política do Presidente Lula. Mas a redução na diplomacia presidencial afetou a participação proativa do Brasil na política global (Saraiva, 2014. pp. 27-28).

Já o discurso do ex-ministro José Serra difere, de maneira significativa, comparado aos dos outros dois discursos. É importante ressaltar, antes de tudo, que a mudança no Itamaraty dá-se em um contexto delicado, em que a presidente Dilma Rousseff sofre um processo de impeachment fruto de uma série de ações que podem ser traçadas desde o seu primeiro mandato. Como aponta Forman e Myers (2016), os protestos ocorridos em 2013, tendo como estopim o aumento do preço das passagens de ônibus, aliado a uma crise política que se agrava com as descobertas de grandes esquemas de corrupção que afetaram fortemente tanto a elite política do país como a elite política do Partido dos Trabalhadores (PT), tendo a Lava Jato como símbolo, minaram a imagem da presidente perante a população e os políticos.

Essa ruptura constitucional teve influência na política externa, levando a claras mudanças com relação ao governo Dilma. Nunes e Gonzalez (2017) argumentam que uma das primeiras mudanças é o fato do ex-ministro José Serra ser um "político strictu sensu", diferentemente de seus antecessores que eram diplomatas de carreira. Tal mudança, segundo Coronato (2016), representou a quebra de uma tradição tácita de buscar um substituto na própria burocracia do Itamaraty. Lima (2005) demonstra que entre 1985 e 2003, apenas três nomeações para Ministério das Relações Exteriores foram para políticos, em um total de dez. Para Nunes e Gonzalez (2017):

[José Serra] buscou, ao mesmo tempo, internacional, marcada pelo acirramento da competição internacional nos âmbitos econômico, político e mili$\operatorname{tar}$ (Nunes \& Gonzalez, 2017, p. 31) alinhar-se às diretrizes do novo governo nacional, liderado pelo então interino Michel Temer, e também lidar com a nova conjuntura

Em seu discurso de posse, José Serra apresentou a "Nova Política Externa Brasileira", resumida em dez diretrizes, sendo "seis dessas relacionadas à abertura de mercado ou reformulação da posição brasileira, seja na integração regional ou nos fóruns multilaterais" (Santos, 2016). Assim, analisando a nuvem de palavras, nota-se, em destaque, a palavra "comércio", além da palavra "investimento" e "comercial" em segundo plano (Figura 5). Essa ênfase em questões econômicas, pode estar correlacionada com a crise político-econômica que o país tem passado ultimamente. 


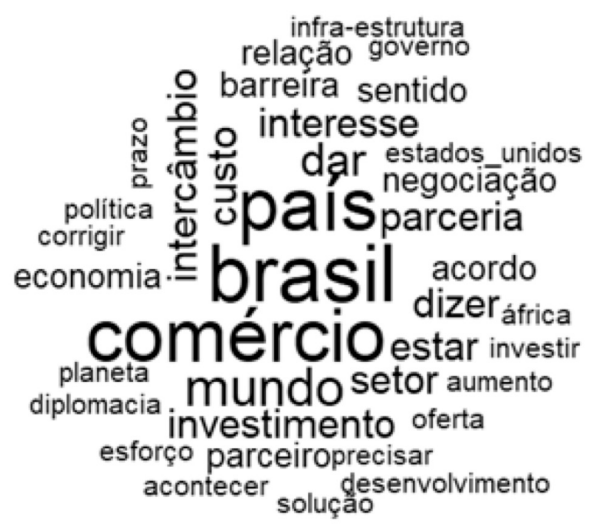

Figura 5. Nuvem de Palavras - José Serra

Fonte: Ministério das Relações Exteriores e FUNAG.

Rezende (2016 apud Nunes \& Gonzalez, 2017) ressalta que a "principal metamorfose é a suposta desideologização da política externa brasileira e o redirecionamento das relações internacionais do eixo sul-sul para o norte-sul". Essa suposta desideologização, é observada no trecho em que o ex-Ministro afirma que "A diplomacia voltará a refletir de modo transparente e intransigente os legítimos valores da sociedade brasileira e os interesses de sua economia, a serviço do Brasil como um todo e não mais das conveniências e preferências ideológicas de um partido político e de seus aliados no exterior" ${ }^{[14]}$. Além disso, José serra, aponta que a "política externa será regida pelos valores do Estado e da nação, não do governo e jamais de um partido"[15].

Desse modo, pode-se observar no discurso uma nova proposta de reordenamento das relações exteriores do Brasil, buscando privilegiar acordos bilaterais, em detrimento do multilateralismo, com as economias do centro do capitalismo global, como Estados Unidos da América, que aparece na nuvem de palavras. Um exemplo dessa ação de privilegiar acordos bilaterais é que, no âmbito regional, o processo de integração por meio da União das Nações Sul-Americanas (UNASUL) e da iniciativa para a Integração da Infraestrutura Regional Sul-Americana (IIRSA) foram sendo menos preteridas do que reuniões bilaterais (Nunes \& Rodriguez, 2017).

É válido pontuar, como argumenta Santos (2016), que as medidas de José Serra demonstram uma ruptura com relação à política externa brasileira "altiva e ativa" do governo Lula, liderada por Celso Amorim, que caracterizou-se "por uma inserção autônoma e dinâmica do Brasil no cenário internacional, com destaque para a Cooperação sul-sul (CSS) e a diversificação de parcerias" (Nunes \& Rodriguez, 2017).

14. Disponível em: <http://www.itamaraty.gov.br/pt-BR/discursos-artigos-e-entrevistas/ministro-das-relacoes-exteriores-discursos/14038-discurso-do-ministro-jose-serra-por-ocasiao-da-cerimonia-de-transmissao-do-cargo-de-ministro-de-estado-das-relacoes-exteriores-brasilia-18-de-maio-de-2016> (acesso em: 25 de jun. 2016).

15. Ibdem. 


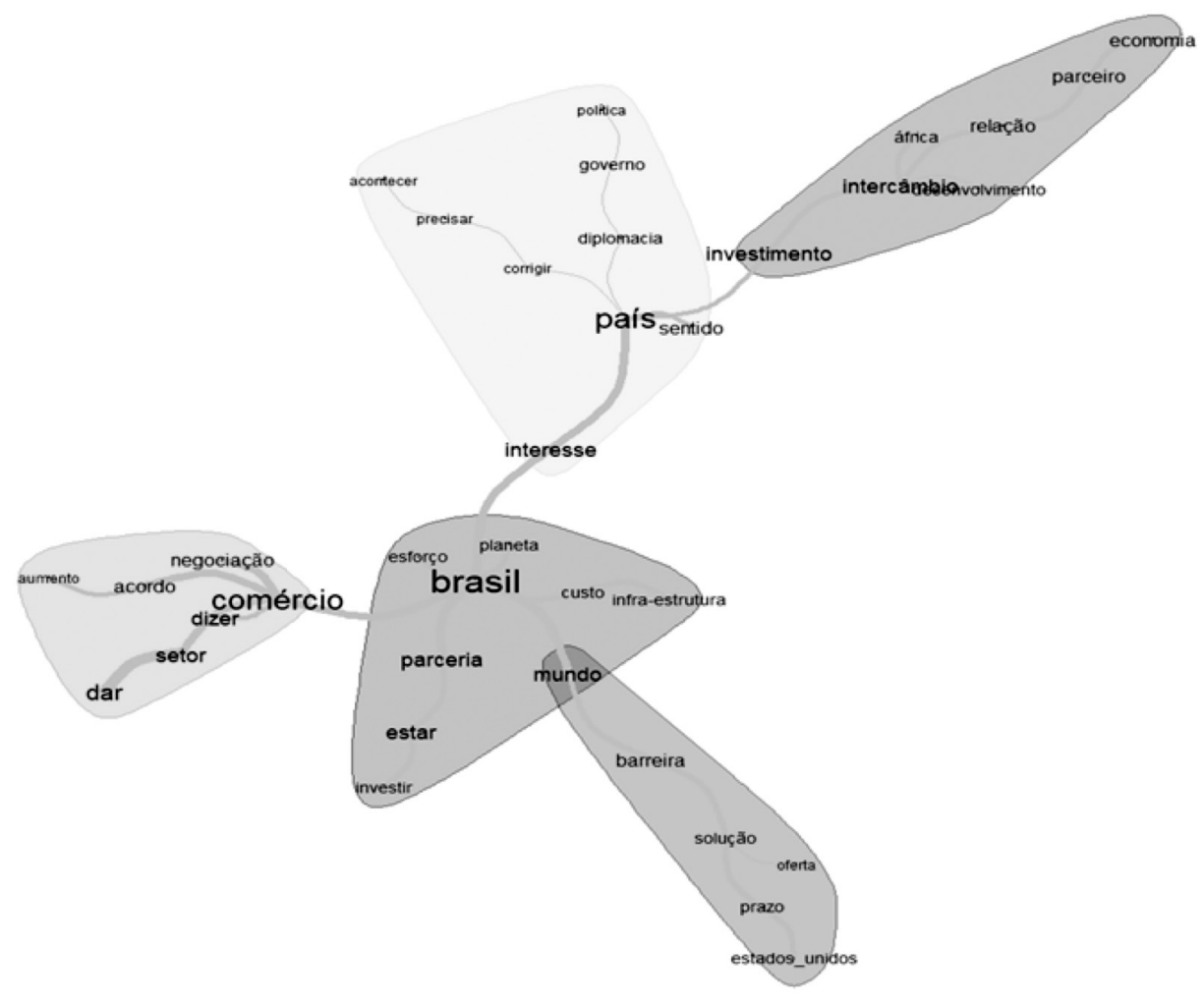

Figura 6. Similitude - José Serra

Fonte: Ministério das Relações Exteriores e FUNAG.

A crise econômica vivida no país, aliada a uma crise política que piorava o panorama econômico, levando, como argumento principal, ao impedimento da presidente Dilma Rousseff, fizeram com que o ex-ministro José Serra, no seu discurso de posse, falasse, principalmente, para os agentes econômicos internacionais, buscando mostrar o compromisso do atual governo na retomada da estabilização econômica do país. Nunes e Rodriguez (2017) demonstram tanto o papel desempenhado pelo ex-ministro José Serra, quanto do presidente Temer, na procura para atrair investimentos para o país, seja no âmbito regional, na busca de liberalizar o comércio dentro do Mercado Comum do Sul (MERCOSUL) ou no âmbito mais global, como é visto na VII Cúpula dos BRICS que ocorreu entre os dias 15 e 16 de outubro de 2016 na Îndia, em que ressaltou-se a preocupação com o protecionismo e a importância do bloco. Assim, observam-se os novos rumos na política externa que podem ser definidos pela retração política e pelo pragmatismo econômico, como afirmam Nunes e Rodriguez (2017). 


\section{Conclusão}

O presente artigo buscou, através da análise de conteúdo do discurso de posse de Ministros das Relações Exteriores, analisar quais as principais diretrizes da política externa brasileira nos governos Lula, Dilma e Temer. Por meio do auxílio de análises estatísticas, o trabalho procurou comparar os discursos do ex-ministro Celso Amorim, de Antônio Patriota e do ex-Ministro José Serra. É importante pontuar que o artigo não buscou fazer uma análise detalhada sobre a política externa dos governos, apenas buscou observar quais as diretrizes foram apresentadas.

As principais limitações encontradas na construção do artigo foram a falta de material metodológico sobre o software IRAMUTEQ que, apesar de ser utilizado com cada vez mais frequência, ainda não possui um aporte teórico, além do escasso material acadêmico sobre a política externa no governo Temer. Em relação ao método utilizado, as limitações pontuadas, seriam as já apontadas pela literatura especializada que é o risco de contaminar a análise com pré-conceitos do observador (Thompson, 1995), tendo em vista de que se trata de uma metodologia qualitativa. Além disso, Thompson (1995), Bateson (2000) e Chase (2008) alertam para o descolamento da análise e seu contexto histórico, ou seja, a análise corre o risco de tornar-se anacrônica. Por último, seguindo o princípio de replicabilidade de King (1995), os dados e os comandos serão disponibilizados posteriormente para todos que quiserem testar a validade do trabalho.

Os resultados indicam a aceitação da hipótese que, durante os governos Lula e Dilma, houve uma tentativa de desenvolver e aprofundar as relações sul-sul e de cooperação com os demais países emergentes, enquanto o governo Temer propôs diretrizes com tendências a relações norte-sul e com um grande enfoque na economia. Para Cervo (2008) e Amorim Neto (2011), a orientação ideológica dos governos tem mais influência sobre a política externa do que a mudança de regime político. Isso fica claro na transição dos governos do Partido dos Trabalhadores (PT) para o Partido do Movimento Democrático Brasileiro (PMDB). Se os governos petistas foram capazes de desenvolver as diretrizes propostas de maneira satisfatória ou se o governo Temer conseguirá, também, desenvolver suas diretrizes são objetos de estudos para outros trabalhos e que nesse artigo não cabe.

\section{Agradecimentos}

Agradeço a Nayanna Sabiá e Neto Galdino os inúmeros comentários e incentivos. Agradeço ainda aos pareceristas anônimos da Revista Portuguesa de Ciência Política pelas excelentes sugestões. Quaisquer incorreções remanescentes são de minha total responsabilidade

\section{Referências}

Agência Brasil. (2011). Saída para crise econômica é combater o desemprego, diz presidenta. Governo do Brasil. Disponível em <http://www.brasil.gov.br/economia-e-emprego/2011/11/ saida-para-crise-economica-e-combater-o-desemprego-diz-presidenta $>$. 
Agência Brasil. (2016). Michel Temer viaja à Ásia para participar de cúpula do BRICS e atrair mais investimentos. Comex do Brasil. Disponível em <https://www.comexdobrasil. $\mathrm{com} /$ michel-temer-viaja-a-asia-para-participar-de-cupula-do-brics-e-atrair-mais-investimentos/>.

ALADI - Associação Latino-Americana de Integração. O que significou a substituição da ALALC pela ALADI? ALADI - Associação Latino-Americana de Integração. Disponível em <http://www.aladi.org/nsfaladi/preguntasfrecuentes.nsf/009c98144e0151fb03256ebe005e795d/cf2ded02ef8e4a6c03256ed100613e5d?OpenDocument>.

Almeida, P. R. (1998). Relações internacionais e política externa do Brasil. Porto Alegre, Brasil: Editora da Universidade.

Amorim, C. (2013). Breves narrativas diplomáticas. São Paulo, Brasil: Benvirá.

Amorim Neto, O. (2011). De Dutra a Lula: a condução e os determinantes da política externa brasileira. Rio de Janeiro, Brasil: Elsevier.

Araújo Jorge, A. G. (1948). Ensaios da História e crítica (pp. 105-14). Rio de Janeiro, Brasil: Ministério das Relações Exteriores.

Bardin, L. (2011). Análise de conteúdo. Lisboa, Portugal: Edições 70.

Bateson, G. (2000). Steps to an ecology of mind: collected in anthropology, psychiatry, evolution, and epistemology. Chicago, United States of America: University of Chicago Press.

Camargo, B.V.\&Justo, A. M.(2013). Tutorial para uso do software textual de análise.IRAMUTEQ. Disponível em <http://www.iramuteq.org/documentation/fichiers/tutoriel-en-portugais $>$ (acesso em 15 out. 2016).

Campos, T. (2014). Análise de discurso e Relações Internacionais: os discursos sobre paz e segurança na África no Conselho de Segurança da ONU (TCC). Brasil: Universidade Federal de Santa Catarina.

Carvalho, T. C. O. \& Ribeiro, R. A. (2014). Política externa brasileira na construção da ordem ambiental internacional: desenvolvimento com sustentabilidade? Proceedings of IX Encontro da $A B C P$ (pp. 1-20). Brasília, Brasil.

Cervi, E. (2016). O que contam os nomes das coligações a prefeito em 2016?. Blog_Em_Público. Disponível em <https://blogempublico.wordpress.com/2016/08/27/o-que-contam-os-nomes-das-coligacoes-a-prefeito-em-2016/> (acesso em 20 nov. 2016).

Cervo, A. \& Bueno, C. (1992). História da política exterior do Brasil. São Paulo, Brasil: Ática.

Cervo, A. \& Lessa, A. C. (2014). O declínio: inserção internacional do Brasil (2011-2014). Revista Brasileira de Política Internacional, 57(2), 133-151. Disponível em <http://goo.gl/ DPmvxo> (acesso em 1 dez. 2016).

Chase, S. E. (2008). Narrative inquiry: multiple lenses, approaches, voices. In N. K. Denzin \& Y. S. Lincoln (Eds.), Collecting and interpreting qualitative materials (pp. 57-94). Los Angeles, United States of America: Sage.

Commission for Social Development. (2012). Poverty eradication (CSocD50). United Nations: Economic and Social Council.

Cornetet, J. M. C. (2014). A política externa de Dilma Rousseff: contenção na continuidade. Conjuntura Austral, 5(4), 111-150. 
Coronato, D. \& Leite, L. (2016). Os novos velhos rumos do Itamary. Núcleo de Estudos Académicos Internacionais (NEAI). Disponível em <http://neai-unesp.org/os-novos-velhos-rumos-do-itamaraty-por -daniel-r-coronato-e-lucas-leite> (acesso em 28 de maio 2017).

Costa da Silva, D. (2015). Política externa é política pública: reflexões sobre a política externa brasileira. Revista NEIBA Cadernos Argentina-Brasil, 4, 13-23.

Costa Franco, A. (2016). Tratados de fixação de limites territoriais. Atlas Histórico do Brasil. Disponível em <https://atlas.fgv.br/verbetes/tratados-de-fixacao-de-limites-territoriais > .

Danese, S. (1999). Diplomacia presidencial. Rio de Janeiro, Brasil: Topbooks Editora.

Dantas, T, S. (1962). Política externa independente. Rio de Janeiro, Brasil: Civilização Brasileira.

Fairclough, N. (2001). Discurso mudança social. Brasília, Brasil: Editora da UnB.

Fingermann, N. (2017). Será o fim dos projetos de Cooperação Sul-Sul brasileira?, Revista Mundorama. Disponível em <https://www.mundorama.net/2017/01/12/sera-o-fim-dos-projetos-de-cooperacao-sul-sul-brasileira-por-natalia-nfingermann/>.

Forman, M. J, \& Myers, E. (2016). Olhando para fora: o engajamento externo brasileiro após Dilma. Cadernos Adenauer, 4, 11-24.

Fonseca, JR. G. (1982). A Legitimidade e outras questões Internacionais - Estudos sobre a Ordem Mundial e sobre a Política Exterior do Brasil num Sistema Internacional em Transformação. Rio de Janeiro, Brasil: Nova Fronteira, pp. 137-248, p. 358.

Fundação Alexandre de Gusmão. Fundação Alexandre de Gusmão Diplomacia Pública, Relações Internacionais e Política Externa. Disponível em <www.funag.gov.br>.

Hill, C. (2003). The changing politics of foreign policy. London, United Kingdom: Palgrave.

IRAMUTEQ. Interface de R pour les analyses multidimensionnelles de textes et de questionnaires. Adjectif Analyses Recherches sur les TICE. Disponível em <http://www.adjectif. net/spip/spip.php?breve662>.

Jaguaribe, H. (1958). O nacionalismo na atualidade brasileira. Rio de Janeiro, Brasil: ISEB.

Justo, A. M. \& Camargo, B. V. (2014). Estudos qualitativos e o uso desoftwares para análises lexicais. Em: Novikoff, C.; Santos, S. R. M. \& Mithidieri, O. B. (Orgs.) Caderno de artigos: X SIAT \& II Serpro (2014: Duque de Caxias, RJ) (Página 37-54). Duque de Caxias: Universidade do Grande Rio "Professor José de Souza Herdy"- UNIGRANRIO, Caderno digital disponível em: <https://lageres.wordpress.com/>. Disponível em $<$ https://www. academia.edu/11753344/Estudos_qualitativos_e_o_uso_de_softwares_para_análises_ lexicais> (acesso em 18 nov. 2016).

Keohane, R. (1988). International Institutions: two approaches. International Studies Quarterly, International Studies Quarterly, 32(4), 379-396 Disponível em: <http://www.rochelleterman.com/ir/sites/default/files/keohane1988.pdf> (acesso em 03 nov. 2016).

King, G. (1995). Replication, replication. Political Science and Politics, 28, 444-452.

Krippendorff, K. (1969). Models of messages: three prototypes. In G. Gerbner, O. R. Holsti, K. Krippendorf, G. J. Paisly, \& P. J. Stone (Eds.), The analysis of communication content. New York : Wiley. 
Lacerda, G. B. de. (2001). Identidade (inter)nacional e política externa do Brasil [Review of the book A identidade internacional do Brasil e a política externa brasileira: Passado, presente e futuro, by C. Lafer]. Revista de Sociologia e Política, 17, 147-150.

Lafer., C. (2014). A identidade internacional do Brasil e a política externa brasileira (3. ${ }^{\text {a }}$ ed.). São Paulo, Brasil: Perspectiva.

Lima, M. R. S. (2005). A política externa brasileira e os desafios da cooperação Sul-Sul. Revista Brasileira de Política Internacional, 8(1), 24-59. Disponível em<http://www.scielo.br/ pdf/rbpi/v48n1/v48n1a02.pdf> (acesso em28 Mai. 2017).

Luiz, R. (2011). A política externa do Regime Militar entre o ranço ideológico e a atuação pragmática. In 3. ${ }^{\circ}$ Encontro Nacional ABRI 2011: Governança Global e Novos Atores, Associação Brasileira de Relações Internacionais, (pp. 1-15).

Marchand, P., \& P. Ratinaud. (2012). L'analyse de similitude appliqueé aux corpus textueles: les primaires socialistes pour l'election présidentielle française. Presented at the $11^{\mathrm{eme}}$ Journées internationales d’Analyse statistique des Données Textuelles, Liège, Belgique.

Ministérios das Relações Exteriores. (2008). Regimento Interno da Secretária de Estado das Relações Exteriores (212). Brasil: Ministério das Relações Exteriores. Disponível em $<w w w . i t a m a r a t y . g o v . b r / i m a g e s / R I S E . p d f>$.

Ministério das Relações Exteriores. Discursos, artigos e entrevistas. Ministério das Relações Exteriores. Disponível em from <http://www.itamaraty.gov.br/pt-BR/discursos-artigos-e-entrevistas/ministro-das-relacoes-exteriores-discursos/14038-discurso-do-ministro-jose-serra-por-ocasiao-da-cerimonia-de-transmissao-do-cargo-de-ministro-de-estado-das-relacoes-exteriores-brasilia-18-de-maio-de-2016>.

Ministério das Relações Exteriores. Ministério das Relações Exteriores. Disponível em <http:// www.itamaraty.gov.br/>.

Miyamoto, S. (2013). Política externa brasileira: 1964-1985. Carta Internacional, 8(2), 3-19.

Moraes, R. (1999). Análise de conteúdo. Revista Educação, 22(37), 7-32.

Mozzatto, A.R. \& Grzybovsky, D. (2011). Análise de conteúdo como técnica de análise de dados qualitativos no campo da administração: potencial e desafios. RAC Curitiba, 15(4), 731-747.

Nunes, R. \& Rodriguez, V. (2017). A política externa brasileira de Temer-Serra: retração política e subordinação econômica. Boletim Conjuntura Nerint, 1(4), 1-91.

Olabuenaga, J. \& Ispizúa, M. (1989). La descodificación de la vida cotidiana: métodos de investigación cualitativa. Bilbao, Espanha: Universidad de Deusto.

Oliveira, H. A. (2005). O conceito de política externa brasileira. São Paulo, Brasil: Editora Saraiva.

O'neill, J. (2001). Building Better Global Economic BRICS (Global Economics no 66). London, United Kingdom: Goldman Sachs Economics. Disponível em <http://www.goldmansachs.com/our-thinking/archive/archive-pdfs/build-better-brics.pdf> (acesso em 17 de fev. 2017).

Pecequilo, C. (2008). A política externa do brasil no século XXI: os eixos combinados de cooperação horizontal e vertical. Revista Brasileira de Política Internacional, 51(2), 136-153. 
Pereira M. (1948). Obras do Barão do Rio Branco, Discursos (IX) (p. 190). Rio de Janeiro, Brasil: Ministério das Relações Exteriores.

Pini, A. M. (2016). A crescente presença chinesa na América Latina: Desafios ao Brasil. Boletim de Economia e Política Internacional, 21, 21-31.

Pinheiro, L. (2004). Política externa brasileira (1889-2002). Rio de Janeiro Brasil: Jorge Zahar.

Pontes, A. N. H. de, Oliveira, D. C. de \& Gomes, A. M. T. (2014). Os princípios do Sistema Único de Saúde estudados a partir da análise de similitude. Revista Latino-Americana de Enfermagem, 22(1), 1-9.

Porcino, A. C. (2016). QUEM VOCÊ PENSA QUE ELA É? Representações sociais de estudantes do Bacharelado Interdisciplinar em Saúde da Universidade Federal da Bahia acerca da travesti (Masters dissertation). Universidade Federal da Bahia, Brasil.

Rezende, L. P. (2016). O Dissenso de Washington e a política externa de Temer e Serra. Carta Capital. Disponível em <http://www.cartacapital.com.br/blogs/blog-do-grri/o-dissenso-de-washington-e-a-politica-externa-de-temer-e-serra> (acesso em 25 de maio 2017).

Ribeiro, W. G. (2016). A política externa brasileira dos governos Lula da Silva (2003-2010) e Dilma Rousseff (2011-2014) para a Palestina: ruptura ou continuidade? TCC (graduação). Brasil: Universidade Federal de Santa Catarina.

Ribeiro, R. A. \& Carvalho, T. C. O. (2015). A política externa brasileira pós transição democrática: a análise de conteúdo de discursos. In 5. Encontro Nacional da ABRI Redefinindo a Diplomacia num Mundo em Transformação, (pp. 1-18). Brasil: Belo Horizonte.

Ribeiro, P. F. \& Junior, H. (2013). As relações bilaterais Brasil-China: uma relação em processo de afirmação. Revista Carta Internacional, 8(1), 165-187.

Rinaldi, A. L. (2015). A política externa do governo Lula: Identificações e orientações (Masters dissertation). UNICAMP, Campinas.

Russell, R. (1990). Política exterior y toma de decisiones en América Latina. Buenos Aires, Argentina: Grupo Editor Latinoamericano.

Safatle C. (2011). 2008 e 2011 são crises com impactos distintos sobre o Brasil. ValorInvesteA Opinião Independente. Disponível em <https://www.valor.com.br/valor-investe/ casa-das-caldeiras/1034948/2008-e-2011-sao-crises-com-impactos-distintos-sobre-o-brasi>.

Santos, M. (2016). Política externa brasileira Interina: diplomacia sob nova direção. Carta Capital. Disponível em <http://www.cartacapital.com.br/blogs/blog-do-grri/politica-externa-brasileira-interina-diplomacia-sob-nova-direcao> (acesso em 20 de maio 2017).

Saraiva, M. G. (2014). Balanço da política externa de Dilma Rousseff: perspectivas futuras? Relações Internacionais, 44, 25-35.

Silva, D. C., Ribeiro, R. A. \& Carvalho, T. C. O. (2014). Análise de conteúdo de discurso: interpretando a política externa brasileira na fala de seus líderes políticos. In IX Encontro da ABCP, (pp. 1-22). Brasília.

Silva, D. C. (2014). Política externa brasileira de Direito Humanos: analisando a trajetória dos Direitos Humanos após a redemocratização por meio da Análise de discurso. In IX Encontro da ABCP, (pp. 1-22). Brasília. 
Stuenkel, O. (2014). Brazilian foreign policy: Game over? Post Western World. Disponível em $<$ http://www.postwesternworld.com/2014/01/28/brazilian-foreignpolicy/> (acesso em 6 maio 2017).

Thompsnon, J. B. (1995). Ideologia e cultura moderna: teoria social crítica na era dos meios de comunicação de massa (2. ${ }^{\mathrm{a}}$ ed.). Rio de Janeiro, Brasil: Vozes.

Vigevani, T. \& Cepaluni, G. (2007). A política externa de Lula da Silva: a estratégia da autonomia pela diversificação. Contexto Internacional, 29(2), 273-335.

Vizentini, P. (2004). A política externa do regime militar brasileiro (2. ${ }^{\mathrm{a}}$ ed.). Porto Alegre, Brasil: Ed.UFRGS.

\section{Sobre o autor}

PEDRO FONSECA é graduando em Ciência Política com ênfase em Relações Internacionais pela Universidade Federal de Pernambuco, Brasil. Pesquisador associado e bolsista do Instituto de Estudos da Ásia (IEASIA/UFPE) tem interesse em Economia Política Internacional, Política Externa Comparada e Política Externa Chinesa.

\footnotetext{
About the author

PEDRO FONSECA holds a degree in Political Science with an emphasis in International Relations from the Federal University of Pernambuco, Brazil. He is a Research Associate and Investigation fellowship of the Institute of Studies of Asia (IEASIA / UFPE) and has interests in International Political Economy, Comparative Foreign Policy, and Chinese Foreign Policy.
} 